\title{
COMPORTAMENTO DO MERCADO DE PREÇOS DE FRETES RODOVIÁRIOS DE AÇÚCAR PARA EXPORTAÇÃO NO ESTADO DE SÃO PAULO ${ }^{1}$
}

\author{
Leandro Bernardino de Carvalho ${ }^{2}$ \\ José Vicente Caixeta Filho
}

Resumo - Atualmente, o Brasil se destaca como o maior produtor e exportador de açúcar do mundo; portanto, espera-se que muitos dos fatores envolvidos no processo de produção e comercialização do produto apresentem — se não a melhor — uma forma bem definida e capaz de restringir custos mais elevados. Nesse contexto, o presente trabalho buscou caracterizar o processo de distribuição do açúcar produzido no Estado de São Paulo, indicando de forma sucinta os principais agentes envolvidos com o setor, o fluxo observado pelo produto até sua entrega final e a evolução dos preços do transporte e dos preços finais do produto ao longo do ano. O método utilizado para isso é referenciado pela aplicação de ferramental econométrico específico, a partir do levantamento dos dados primários pertinentes. De modo geral, observou-se que o setor de transportes do mercado açucareiro é bastante competitivo e aberto à entrada e à saída de empresas relacionadas ao setor. Os preços negociados do serviço de transporte são definidos no momento da demanda pelo serviço, dependendo da situação e necessidade apresentada. Mesmo assim, a variação nos preços dos fretes do açúcar para exportação segue uma tendência bastante característica, observando-se crescimento em períodos de grande produção do açúcar e queda em períodos de baixa produção.

Palavras-chave: frete, transporte, açúcar, logística, exportação.

Recebido em 03/01/2007. Aceito em 05/03/2007.

Mestrando em Engenharia de Produção - EESC/USP. E-mail: leandro@esalq.usp.br.

Professor Titular do Departamento de Economia, Administração e Sociologia - ESALQ/USP.

E-mail: jvcaixet@esalq.usp.br. 


\section{Introdução}

Com aproximadamente 35\% do PIB nacional em 2004 e crescimento próximo a 4,5\% a.a., o agronegócio brasileiro destaca-se como uma das principais atividades da economia nacional e, no espaço internacional, ocupa patamares elevados, através do sucesso dos vários produtos agropecuários negociados em sua pauta de exportação. O agronegócio também é responsável pelo emprego da maior parte da População Economicamente Ativa (PEA) do País, com 37\% do total em 2004 (Procana, 2005).

No entanto, algumas distorções ainda afetam profundamente o setor, levando a competitividade brasileira perante os demais concorrentes a ser questionada. Nesse sentido, dentre os gargalos ainda existentes questão fundiária, transgênicos, créditos -, atualmente é de extrema importância ressaltar a deficiência de equipamentos e informações para o setor de transporte e armazenagem. Segundo Rodrigues (2004), a falta de infra-estrutura pode resultar em retenção da produção no campo, uma vez que os produtores rurais podem ficar sem meios para comercializar ou estocar seus produtos, o que caracterizaria a chamada "perspectiva da crise de abundância".

Conforme Castro (1995, citado por Caixeta Filho, 2001), a logística eficiente é condição básica para a competitividade de todos os setores da economia, já que esta busca orientar os processos produtivos, atendendo aos requisitos dos mercados consumidores quanto a qualidade dos insumos e produtos, prazos e entregas, assistência técnica e inovações. Assim, o agribusiness se insere nesse contexto, principalmente porque hoje se observa dentro desse setor uma dinâmica nunca antes constatada na oferta de produtos, assim como uma importância econômica muito grande nas contas nacionais.

Um produto do agronegócio nacional merece atenção especial na área de estudos e pesquisas voltadas aos setores de infra-estrutura e comércio internacional: o açúcar, o qual vem se destacando, há anos, como o segundo 
produto mais participativo da pauta de exportações nacional, deixando o Brasil como o seu maior exportador mundial, representando algo em torno de $31 \%$ do total do produto exportado mundialmente (USDA, 2005).

Com $20 \%$ da produção mundial de açúcar (aproximadamente 27 milhões de toneladas das 142 milhões produzidas mundialmente), a posição do Brasil, no ano de 2004, se consolidou perante o mercado internacional desse produto e seus principais concorrentes (USDA, 2005). Nesse contexto, o Estado de São Paulo, com aproximadamente 61\% da safra açucareira 2003/04 (UNICA, 2005), se destaca como principal produtor brasileiro.

O setor de açúcar é um dos que mais sofrem com os problemas de infraestrutura precária nacional, e um dos principais fatores que colaboram para a permanência dessa situação é a falta de investimentos e informações no âmbito logístico, que, por sua vez, provoca custos adicionais muito elevados, os quais se refletirão diretamente no valor final dos produtos produzidos pelo setor.

Por exemplo, o sistema de transporte utilizado pelo setor para o escoamento do açúcar destinado às exportações apresenta problemas que vão desde a idade avançada da frota de caminhões (visto que o modal rodoviário é responsável por, aproximadamente, $90 \%$ da distribuição do produto) até a alta competição pelo transporte disponível entre usinas e outros agentes agroindustriais.

De acordo com Soares et al. (1997), o mercado de frete é bastante competitivo e o preço é determinado pelas interações de específicos tipos de demanda, oferta e ambiente. Os valores disponíveis para eventuais análises incluem os chamados fretes técnicos, calculados com base em estimativas de custos variáveis e fixos. Esses valores, entretanto, têm se distanciado bastante daqueles efetivamente praticados para o transporte de commodities agrícolas.

Segundo Caixeta Filho (1996), o suporte logístico tem sido uma barreira ao desenvolvimento agroindustrial brasileiro; nos últimos anos, isso fica 
mais claramente externado através das preocupações de empresários e funcionários do governo, dedicados a identificar o que vem sendo chamado de "Custo Brasil", ou seja, o conjunto de distorções que torna a economia brasileira menos eficiente do que a de seus principais concorrentes. Nesse sentido, o transporte é a atividade mais importante prevista dentro do setor logístico de uma empresa.

Diante desses fatores, fica clara a necessidade de uma reformulação ou, talvez, uma melhor coordenação do setor agroindustrial no âmbito logístico, com o intuito de minimizar custos, promover maior circulação de informações sobre o tema e, conseqüentemente, garantir maior segurança aos agentes envolvidos no processo de produção e comercialização do produto e, principalmente, elevar o País a uma posição mais competitiva no cenário internacional.

\section{Objetivos}

O presente estudo buscou identificar as principais características envolvidas no mercado de frete rodoviário do açúcar para exportação em São Paulo, como: os agentes envolvidos no processo de transporte do produto e o comportamento específico dos valores de preços de fretes praticados. $\mathrm{O}$ trabalho procurou também sugerir uma referência para a regionalização das principais áreas produtoras do Estado, a fim de facilitar e, ao mesmo tempo, balizar investimentos e futuros estudos mais específicos para o setor. Por fim, a orientação e a identificação de potenciais focos de investimentos por parte tanto de agentes públicos quanto privados - a partir dos resultados obtidos — também constituíram parte importante dos objetivos deste estudo.

\section{Material e métodos}

A aplicação do método utilizado neste estudo pode ser dividida em duas frentes distintas: 
- Aplicação de questionários - abrangendo o tema do trabalho - em usinas e transportadoras especializadas no transporte do açúcar, com o objetivo de buscar dados mais específicos do setor e que possam vir a auxiliar a argumentação em torno das várias análises e premissas realizadas no decorrer do trabalho.

- Utilização de modelo econométrico referenciado por Hoffmann (1998) para calcular os índices sazonais do valor do frete do açúcar e do seu preço final, buscando, assim, uma análise comparativa mais confiável entre esses indicadores.

\section{a) Fonte e Especificação dos Dados}

De modo geral, além do processo de pesquisa de campo para coleta dos dados empregados no presente estudo, outras cinco fontes de dados foram utilizadas para complementar a pesquisa:

- Anuário da Cana, do ProCana - Centro de Informações Sucroalcooleiras.

- Sistema AliceWeb, do Ministério da Indústria, Desenvolvimento e Comércio.

- Cepea (Centro de Estudos Avançados em Economia Aplicada).

- UNICA (União da Agroindústria Canavieira do Estado de São Paulo).

- Sifreca (Sistema de Informações de Fretes).

Durante o período de pesquisa a campo, coleta e análise dos dados deste trabalho, algumas especificações referentes ao processo de escoamento do açúcar foram observadas e definidas, visando o melhor entendimento e conhecimento dos resultados e conclusões a serem apresentados nos tópicos subseqüentes. Nesse sentido, são de fundamental importância o esclarecimento do modo pelo qual o açúcar é comercializado e 
transportado e, também, a forma pela qual (incluindo os equipamentos envolvidos) esse processo ocorre.

Os diferentes modelos de embalagens utilizadas no processo de transporte do açúcar para exportação se destacam como fatores fundamentais no momento da formação do frete do produto, bem como caracterizam os diferentes tipos de demandas pelo produto. Dentre as principais embalagens usadas no transporte do açúcar para exportação, podem ser destacadas:

1. Saca Solta: diz respeito à saca com capacidade para acondicionamento de $50 \mathrm{~kg}$ de açúcar, exigindo bom número de trabalhadores braçais durante seu manuseio; é o padrão de embalagem associado ao frete mais barato, se comparado com as demais embalagens; vem perdendo espaço para outros tipos de embalagens, ficando, em sua maioria, restrita ao mercado interno.

2. Big Bag: embalagem que comporta $1.200 \mathrm{~kg}$ de açúcar; é utilizada somente em casos de demandas muito específicas, principalmente as industriais; devido à dificuldade de se esgotar exatamente a sua capacidade e às novas tecnologias de embalagens existentes, esse padrão de embalagem vem perdendo espaço no mercado.

3. Granel: atualmente, devido à sua maior eficiência no momento do carregamento e descarregamento do produto, é o padrão mais utilizado pelos agentes de mercado. Em razão do maior grau de exigências que esse modelo demanda, caracteriza-se como um frete ligeiramente mais caro, se comparado aos outros padrões de embalagem.

Outro fator de extrema importância para entendimento do transporte do açúcar para exportação e também decisivo no momento do cálculo do valor do frete é o tipo de equipamento utilizado no serviço de transporte, ou seja, o padrão de caminhão usado para esse serviço. Hoje, pode-se encontrar em grande parte do mercado dois tipos distintos de caminhões 
que servem ao setor de transporte do açúcar e, em geral, de produtos agrícolas. São eles:

1. Graneleiro: são caminhões com capacidade, normalmente, para 28 toneladas e que comportam os três tipos de embalagens citados anteriormente. Por não possuírem a caçamba móvel, necessitam de tombadores ${ }^{4}$ para efetuar o serviço de descarga nos portos ou em suas origens. Atualmente, podem-se encontrar graneleiros com capacidade para 40 toneladas - bitrens - e também para 60 toneladas - rodotrens.

2. Basculante: são caminhões com as mesmas características dos graneleiros, porém possuem sistema hidráulico para movimentação da caçamba e, portanto, não necessitam de nenhuma outra tecnologia para descarregamento do produto. Atualmente, novas tecnologias estão sendo testadas com os caminhões basculantes no transporte do açúcar, para que sua capacidade seja ampliada para 40 ou até 60 toneladas, como já observado nos graneleiros.

Dados obtidos em terminais de açúcar localizados no Porto de Santos indicam que, enquanto um caminhão graneleiro leva de 10 a 15 minutos para descarregar uma carga de 28 toneladas de açúcar, um caminhão basculante necessita de somente 30 segundos para efetuar a mesma tarefa. Portanto, é evidente que a demanda pelo caminhão basculante é maior, o que tem como principal conseqüência um valor de frete mais elevado.

Por fim, é interessante e bastante importante que algumas definições sejam apresentadas sobre os agentes envolvidos no processo de comercialização e movimentação do açúcar, a fim de melhor entendimento do ambiente do transporte de açúcar para exportação. São eles:

Sistema mecânico utilizado para descarregar o caminhão em armazéns. Basicamente, são rampas que inclinam o caminhão em, aproximadamente, 45 o do solo. 
1. Tradings: são empresas responsáveis pela negociação do produto com os compradores internacionais e, também, responsáveis pela contratação e controle do transporte do açúcar até a sua entrega ao navio - a partir de onde se torna de responsabilidade do comprador. Normalmente, as tradings representam pequenas usinas ou grupos delas. Atualmente, no País, há tradings representando até mais de 30 unidades produtoras diferentes.

2. Transportadoras: são empresas que prestam serviços às tradings para o escoamento do produto, ou seja, empresas que se responsabilizam pelo transporte do açúcar da unidade produtora até os navios, nos portos. Normalmente, essas empresas possuem frotas de caminhões próprios e, quando necessário, se utilizam de serviços de terceiros para suprir a demanda pelos seus serviços.

3. Agências de Cargas: são empresas que atuam de modo muito parecido ao das transportadoras, porém não possuem as mesmas responsabilidades que elas, ou seja, não oferecem serviços de seguros e não possuem a mesma infra-estrutura que as transportadoras frotas de caminhões, diversos funcionários etc. Essas empresas operam na captação de caminhoneiros autônomos para servir às transportadoras ou, diretamente, às tradings.

4. Caminhoneiros Autônomos: são pessoas físicas que possuem seu próprio caminhão e prestam serviços para as tradings, transportadoras ou agências de cargas. Normalmente, esse tipo de agente já possui acordos ${ }^{5}$ previamente fechados com um desses agentes no início do período de escoamento.

\section{b) Cálculo dos Índices Sazonais ${ }^{6}$}

Admitindo-se preços mensais do açúcar e do seu frete, de janeiro a dezembro, durante $n$ anos, e que seja $P_{t}$ a t-ésima observação nessa 
série de preços mensais, o preço em um certo mês pode ser representado por $P_{i j}, \operatorname{com} i=1, \ldots, n$ indicando o ano e $j=1, \ldots, 12$ indicando o mês, e os índices $t, i$ e $j$ seguem a relação:

$t=12(i-1)+j$

Utiliza-se assim um modelo em que o preço é o resultado do produto de três componentes:

- uma tendência exponencial $A B^{t}=\exp \{a+b t\}$, em que $a=\ln A$ e $b=$ $\ln B$ são parâmetros;

- um componente estacional adimensional $\varepsilon_{j}$ tal que $\prod_{j=1}^{12} \varepsilon_{j}=1 ; \mathrm{e}$

- um fator aleatório adimensional $U_{t}, \operatorname{com} \mathrm{E}\left(\ln U_{t}\right)=0$.

Portanto, tem-se:

$P_{t}=P_{i j}=A B^{t} \varepsilon_{j} U_{t}$

Aplicando logaritmos neperianos, obtém-se:

$\ln P_{t}=a+b t+e_{j}+u_{t}$

em que $\ln \varepsilon_{j}=e_{j}$ e $\ln U_{t}=u_{t}$

A seguir, utilizando a média geométrica móvel centralizada de 12 meses da série de preços representada por Gt, verifica-se que gt $=\operatorname{lnGt}$, onde:

$G_{t}=\sqrt[12]{P_{t-6}^{0,5} \cdot P_{t-5} \ldots P_{t} \ldots P_{t+5} \cdot P_{t+6}^{0,5}}$ 
Com isso, obtêm-se as diferenças $d_{i j}=d_{t}=\ln P_{t}-g_{t}$ ou $d_{i j}=\ln D_{i j}$, em que $D_{i j}=D_{t}=\frac{P_{t}}{G_{t}}$. Os valores de $100 D_{t}=100 \exp \left\{d_{t}\right\}$ são denominados índices estacionais.

Observa-se assim que $\overline{d_{j}}=\ln D_{j}^{*}$, sendo $D_{j}^{*}$ a média geométrica dos valores de $D_{i j}$ para o $j$-ésimo mês, isto é:

$$
D_{j}^{*}=\left(\prod_{i=1}^{n-1} D_{i j}\right)^{\frac{1}{n-1}}
$$

se $7 \leq j \leq 12 \mathrm{e}$

$$
D_{j}^{*}=\left(\prod_{i=2}^{n} D_{i j}\right)^{\frac{1}{n-1}}
$$

se $1 \leq j \leq 6$.

De acordo com (2), é esperado que o produto das 12 estimativas dos $\varepsilon_{j}$ seja igual a 1 . Então, se o produtório dos $D_{j}^{*}$ for diferente de 1 , cada um deles é dividido pela correção:

$$
C=\left(\prod_{j=1}^{12} D_{j}^{*}\right)^{\frac{1}{12}}
$$


obtendo-se:

$\tilde{\varepsilon}_{j}=\frac{D_{j}^{*}}{C}$

Os valores de $100 \tilde{\varepsilon}_{j}$ são denominados índices sazonais, que caracterizam o padrão de variação estacional do preço do produto.

A dispersão dos $d_{i j}$ relativos a um mês pode ser medida por meio da estimativa do desvio- padrão, dada por:

$s_{j}=\sqrt{\frac{1}{n-2} \sum_{i=1}^{n-1}\left(d_{i j}-\overline{d_{j}}\right)^{2}}$

se $7 \leq j \leq 12$ e por:

$s_{j}=\sqrt{\frac{1}{n-2} \sum_{i=2}^{n}\left(d_{i j}-\overline{d_{j}}\right)^{2}}$

se $1 \leq j \leq 6$

Por definição, o indice de irregularidade $\left(S_{j}\right)$ é $S_{j}=\exp \left\{s_{j}\right\}$. Assim, podem-se obter os limites superior e inferior, respectivamente, multiplicando e dividindo o índice sazonal (100) pelo índice de irregularidade.

O conhecimento da variação estacional dos preços é de suma importância para orientação dos produtores agrícolas e dos comerciantes, bem como para a formulação de política agrícola do governo. Ao consumidor esse conhecimento é de interesse para escolher a melhor ocasião do preço de 
compra de um produto agropecuário. Contudo, o conhecimento do índice sazonal do preço e, em virtude desse trabalho, do frete de um produto agropecuário é essencial para a previsão de seu valor efetivo em determinada época do ano.

Para cálculo do índice sazonal do preço final do açúcar utilizou-se uma série histórica mensal, do açúcar em sacas de 50 kg, da safra 1998/99 à safra 2004/05, fornecida pelo Cepea. Com relação ao índice sazonal do frete rodoviário do açúcar para exportação no Estado de São Paulo, foi utilizada uma série histórica de 1999 a 2005, fornecida pelo Sifreca, envolvendo rotas do açúcar com origens em cidades do Estado e destino ao Porto de Santos.

\section{Resultados e discussão}

a) Principais Características do Ambiente em Estudo

Vem se tornando uma tarefa cada vez mais difícil a quantificação e qualificação de todas as usinas presentes no Estado de São Paulo (bem como no restante do País), uma vez que o grande aumento do interesse e da necessidade pelo álcool combustível tem mobilizado uma série de investidores; conseqüentemente, o número de empresas ligadas ao setor, principalmente usinas e destilarias, cresce consideravelmente a cada dia.

Dessa forma, o presente trabalho colocou o centro das atenções (a fim de quantificar da melhor maneira possível o setor) em usinas que operaram na safra 2003/04, tomando como referência dados fornecidos pela UNICA. Portanto, a partir de 118 unidades produtoras (104 operando no mercado externo), foi realizada uma divisão do Estado em várias regiões específicas produtoras de açúcar, que, de certa forma, apresentam características em comum relacionadas ao seu mercado de frete. 
Além da regionalização em termos da concentração de produção, outro aspecto de extrema importância levado em consideração no decorrer da análise e processamento dos dados presentes no estudo foi a questão dos destinos (portos marítimos) envolvidos no processo de escoamento do produto. Para isso, considerou-se como destino único o Porto de Santos, que registrou uma captação de, aproximadamente, $95 \%$ de todo o açúcar destinado à exportação produzido pelo Estado de São Paulo durante a safra 2003/04 (AliceWeb, 2004).

\section{b) Regionalização do Estado de São Paulo}

Um dos principais resultados deste trabalho é a divisão do Estado em diversas regiões produtoras de açúcar, ou seja, a partir de dados e experiência adquiridos em campo, estabeleceu-se uma divisão-padrão das diversas unidades produtoras de açúcar, buscando, assim, um ferramental auxiliar tanto no entendimento e estudo das oscilações que o mercado de transporte pode apresentar quanto no planejamento e controle de fluxo de carga do açúcar e seu sistema de informação.

A regionalização é, basicamente, fruto do levantamento de dados - via telefone e, principalmente, via pesquisa de campo - junto ao mercado de transporte rodoviário do açúcar. Alguns passos foram devidamente tomados para que se chegasse a um conhecimento efetivo de seus centros produtores de açúcar e, a partir disso, se estabelecessem critérios básicos para a divisão.

Primeiramente, foi realizado um estudo sobre o mercado sucroalcooleiro no Estado de São Paulo, em que foram levantados dados de todas as unidades produtoras e os respectivos números de produção e exportação, a fim de identificar e mensurar pontos estratégicos de produção e comercialização do açúcar para exportação.

De posse de um panorama básico do funcionamento de mercado, iniciaram-se as pesquisas via telefone e via campo, que, por sua vez, 
buscaram, essencialmente, identificar características específicas de cada município produtor, de modo que critérios relevantes para a regionalização fossem observados.

A partir disso, foi possível observar o surgimento de critérios que, segundo o mercado açucareiro e seu sistema de transporte, refletem bem o cenário real em que unidades produtoras estão inseridas:

- Cidades produtoras de açúcar que são centro de regiões metropolitanas são tomadas como cidades-centro das regiões açucareiras, ou seja, as cidades produtoras de açúcar que apresentam infra-estrutura - saúde, transporte, educação etc. - melhor que a de vizinhas próximas possuem maior tendência de abrigarem aglomerados de transportadoras e agentes do mercado de transporte do açúcar.

- As distâncias entre as cidades vizinhas e as cidades-centro devem ser levadas em consideração, pois foi observado que um dos fatores mais importantes na diferenciação do frete é a distância envolvida.

- O frete médio a partir de cada município, inicialmente, deve se aproximar daquele originado a partir da cidade-centro da região em que ela está inserida, ou seja, numa mesma região, as diversas cidades (origens produtoras) disputam o serviço de transporte entre si.

- Presença de centros de informações próximos aos municípios, ou seja, o mercado de fretes do açúcar possui concentrações de transportadoras e agentes que trabalham com esse tipo de negócio; a partir disso, é de extrema importância que os municípios que possuem usinas com serviços de transporte localizados nesses centros permaneçam na mesma região. 
A partir dessas premissas, pôde-se chegar à seguinte divisão (nomeando a região com o mesmo nome de sua cidade central): 1. Araçatuba (16 municípios), 2. Araraquara (8 municípios), 3. Catanduva (11 municípios), 4. Jaú (9 municípios), 5. Limeira (13 municípios), 6. Ourinhos (11 municípios), 7. Pirassununga (8 municípios) e 8 . Ribeirão Preto (16 municípios). A Figura 1 ilustra a localização dessas regiões no mapa do Estado de São Paulo, referenciadas pelos números relacionados anteriormente.

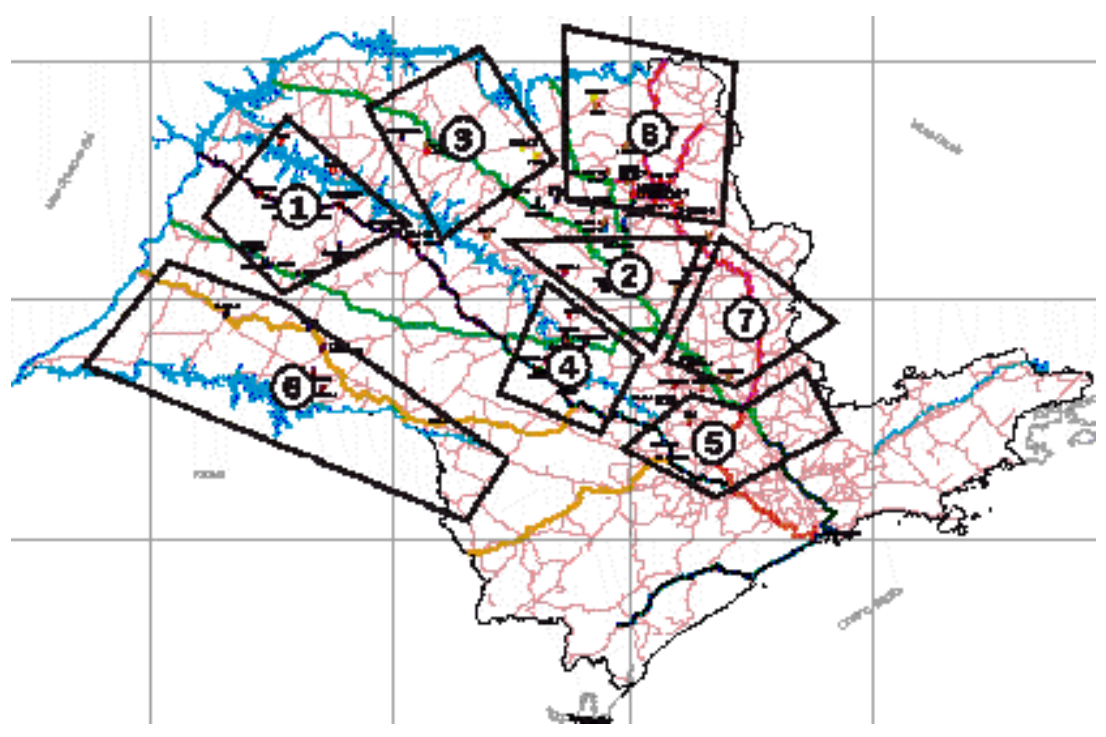

Figura 1 - Visualização das regiões produtoras de açúcar do Estado de São Paulo.

Fonte: Elaborado pelos autores.

c) Fluxograma do Escoamento do Açúcar para Exportação

O acompanhamento do fluxo das etapas pelas quais o açúcar passa durante o processo de transporte demonstrou ser um forte influenciador no processo de tomada de decisões e no processo de formação do preço 
do frete do açúcar, uma vez que, em função das diversas alternativas de fluxo que o açúcar pode vir a percorrer até chegar ao seu comprador, as tomadas de decisões podem ser totalmente distintas. Esse mercado se caracteriza por ser quase em sua totalidade terceirizado, ou seja, cabe ao demandante do serviço de transporte analisar e planejar o melhor trajeto que seu produto deve seguir até seu destino.

Inicialmente, devem-se levar em conta todas as formas possíveis para se movimentar o produto de sua origem até seu destino final. A Figura 2 ilustra o cenário em que o transporte do açúcar está inserido, incluindo os principais agentes envolvidos.

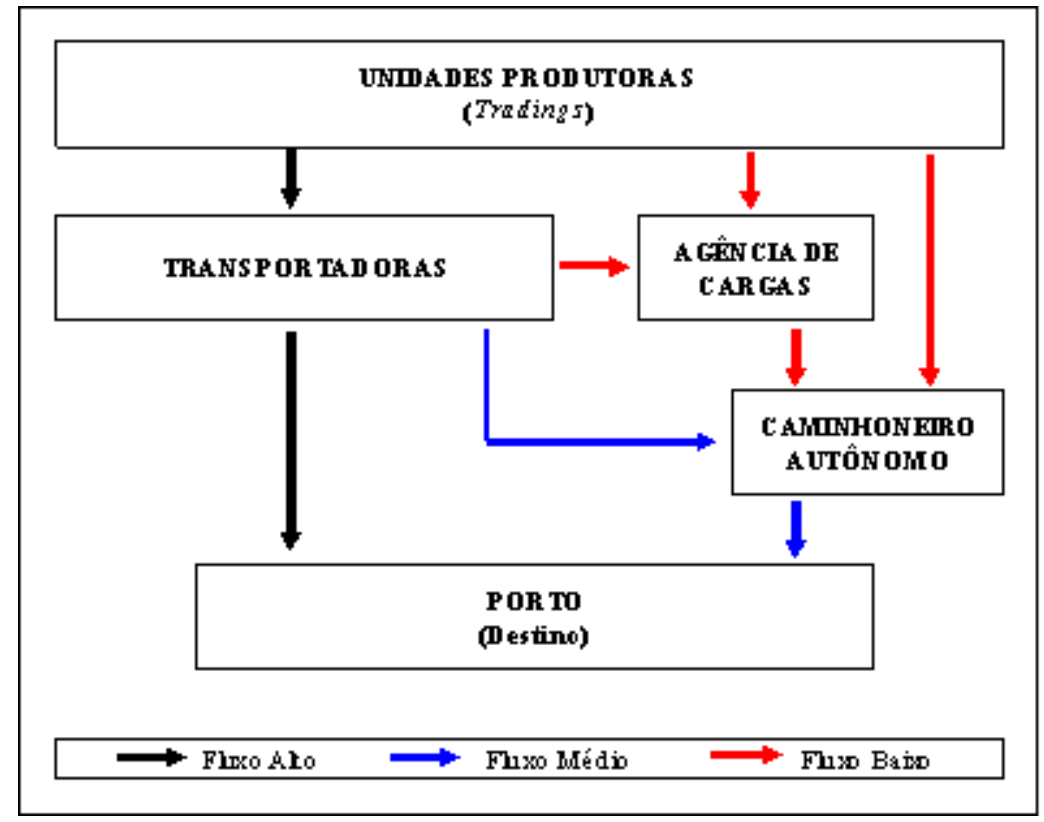

Figura 2 - Fluxograma dos agentes envolvidos no transporte do açúcar para exportação.

Fonte: Elaborado pelos autores. 
Nota-se, a partir da Figura 2, a existência de número pequeno de agentes e alternativas possíveis na ação de transportar o açúcar para exportação. Deve-se considerar que a trading possui três opções de escoamento: primeiramente, ela pode optar por utilizar os serviços da transportadora, que, através de sua frota própria, pode escoar totalmente o produto ou utilizar, caso necessário, os serviços de uma agência de cargas - a fỉm de encontrar caminhoneiros autônomos - caso já possua contato; em segundo lugar - o que vem ocorrendo a partir do maior poder de barganha e qualidade das grandes transportadoras - encontra-se o serviço das agências de cargas, em que cabe, simplesmente, ao agenciador encontrar algum caminhoneiro autônomo para o serviço; por último - caso bastante raro, devido à falta de garantia por parte dos caminhoneiros autônomos e dificuldade na localização destes por parte das tradings - tem-se a contratação direta de um caminhoneiro para efetuar o serviço, opção mais provável em casos de volumes muito baixos.

\section{d) Análise Quantitativa do Frete do Açúcar para Exportação}

De maneira geral, é interessante observar a relação inversa existente entre a evolução do frete do açúcar durante o ano e a evolução de seu preço final, ou seja, os picos mensais no valor do frete do açúcar ocorrem nos períodos de vale do preço do açúcar, e vice-versa, o que deixa evidente os períodos característicos de comercialização e escoamento da produção para o mercado externo (períodos em que tanto a oferta de produto quanto a demanda pelo serviço de transporte são altas). Pode-se notar, portanto, grande variação nos meses iniciais do ano - em que há pouca movimentação do produto - e também nos meses de setembro e outubro - nos quais a movimentação é maior (Figura 3). 


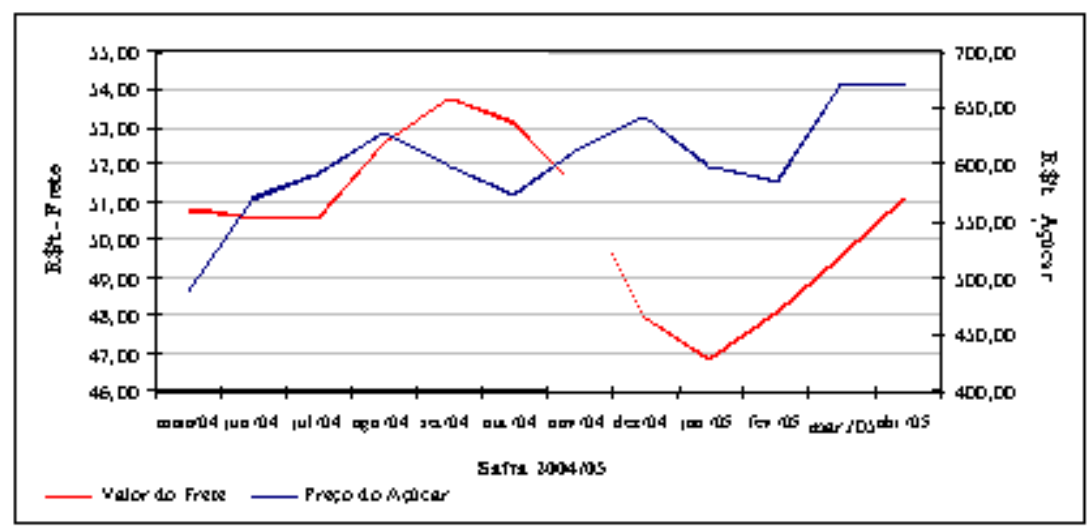

Figura 3 - Evolução das médias mensais dos preços do frete rodoviário e do produto final do açúcar na safra 2004/05 (valores deflacionados - IPC-DI, base em abril/2005).

Fonte: Elaborado pelos autores.

Uma forma mais detalhada de analisar e avaliar o mercado de transporte do açúcar para exportação juntamente com seu mercado de comercialização é por meio dos índices sazonais - conforme realizado a seguir. O índice sazonal do frete do açúcar para exportação no Estado de São Paulo com destino ao Porto de Santos, bem como o índice sazonal do preço do açúcar, podem ser observados na Tabela 1. 
Tabela 1 - Índices sazonais e respectivos limites inferiores e superiores para o frete do açúcar destinado à exportação no Estado de São Paulo e para o preço desse produto

\begin{tabular}{ccccccc}
\hline \multirow{2}{*}{ Mês } & \multicolumn{3}{c}{ Frete do Açúcar } & \multicolumn{3}{c}{ Preço do Açúcar } \\
\cline { 2 - 7 } & Índice & Lim.Inf. & $\begin{array}{c}\text { Lim. } \\
\text { Su. }\end{array}$ & Índice & Lim.Inf. & $\begin{array}{c}\text { Lim. } \\
\text { Sup. }\end{array}$ \\
\hline jan. & 95,94 & 91,42 & 100,69 & 108,42 & 87,25 & 134,73 \\
fev. & 99,57 & 93,82 & 105,67 & 105,48 & 84,05 & 132,37 \\
mar. & 98,14 & 92,99 & 103,58 & 103,98 & 88,07 & 122,77 \\
abr. & 97,72 & 91,64 & 104,20 & 102,35 & 92,11 & 113,74 \\
maio & 99,24 & 96,37 & 102,19 & 88,77 & 76,72 & 102,71 \\
jur. & 99,63 & 95,59 & 103,83 & 88,06 & 72,70 & 106,65 \\
jul. & 100,21 & 95,96 & 104,64 & 90,62 & 76,29 & 107,65 \\
ago. & 102,72 & 99,38 & 106,18 & 99,59 & 85,84 & 115,53 \\
set. & 104,44 & 100,00 & 109,07 & 100,23 & 90,28 & 111,27 \\
out. & 103,98 & 100,60 & 107,48 & 104,18 & 95,22 & 113,98 \\
nov. & 101,52 & 97,65 & 105,55 & 103,60 & 92,79 & 115,66 \\
dex. & 97,29 & 88,98 & 106,36 & 107,67 & 97,43 & 118,98 \\
\hline
\end{tabular}

romle: clavorauo peios autores.

A Figura 4 traz a ilustração de ambos os índices sazonais - frete e preço do açúcar -, com o intuito de estabelecer uma comparação direta entre eles. 


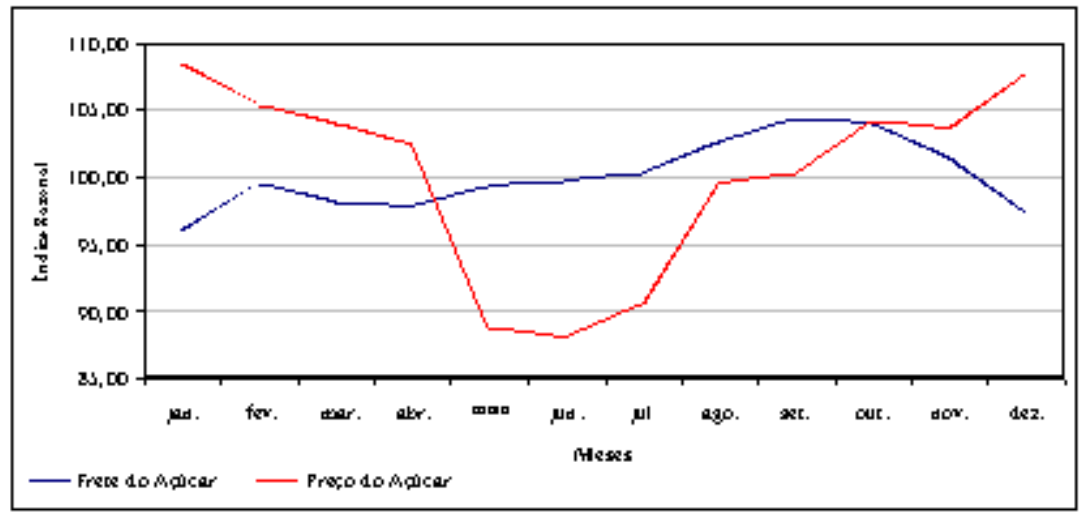

Figura 4 - Variações estacionais do preço do frete rodoviário do açúcar para exportação no Estado de São Paulo e do preço mensal final do produto.

Fonte: Elaborado pelos autores.

Nota-se que quando se inicia a safra da cana-de-açúcar, entre os meses de maio e junho, há queda no preço do açúcar, devido à sua maior oferta. Por outro lado, há maior demanda por fretes rodoviários para transporte da produção, o que pressiona os preços do frete e faz com que ocorra forte elevação no preço do frete rodoviário do açúcar para exportação no mês de agosto. Esse efeito dura até o mês de outubro, quando acaba a maior parte da safra de açúcar, e, conseqüentemente, acarreta queda do preço do frete.

Pela Figura 5, que também mostra a variação do índice sazonal do preço do frete rodoviário do açúcar com destino ao Porto de Santos e a variação estacional do preço do açúcar, percebe-se que nos meses de maio até setembro, ilustrados pelas barras pretas - com destaque para os meses de maio, junho e julho - , o setor de transportes se encontra em melhor situação e os embarcadores de açúcar em pior, pois o preço do frete rodoviário desse produto para exportação é elevado e o preço do açúcar é baixo. Por outro lado, nos meses de novembro a abril, ilustrados pelas barras brancas, com destaque para dezembro e janeiro, a conjuntura se inverte, com a situação para os embarcadores de açúcar se tornando 
melhor; já para o setor de transportes a situação é pior, pois o preço do frete rodoviário do açúcar para exportação é menor.

Pode-se considerar, a partir dessas observações, que o mês de outubro é o ponto de referência para o mercado de transportes no setor sucroalcooleiro, uma vez que a partir desse mês os preços do açúcar e de seu frete começam a observar uma inversão de comportamentos.

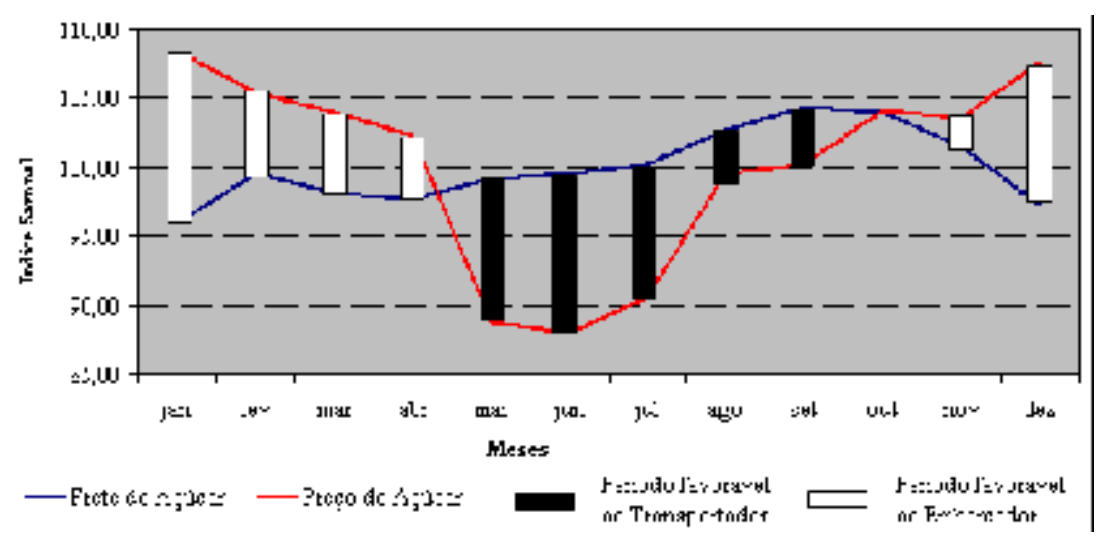

Figura 5 - Ilustração da diferença entre as variações estacionais do preço do frete rodoviário do açúcar para exportação no Estado de São Paulo e do preço mensal final do produto.

Fonte: Elaborado pelos autores.

\section{Conclusões}

O mercado de transportes do açúcar para exportação no Estado de São Paulo, de forma geral, se mostrou bastante aberto e receptivo à pesquisa de campo e via telefone realizada para elaboração deste trabalho. No entanto, esse mercado se mostrou bastante atrasado no que diz respeito à sua organização e ao seu sistema de informação. Por se caracterizar como um setor terceirizado pela agroindústria canavieira, o mercado de transportes apresenta, atualmente, grande competitividade, observando livre entrada para agentes e, assim, envolvendo número significativo de 
participantes, o que, conseqüentemente, resulta em falhas nos sistemas organizacionais que controlam o setor e nos sistemas informacionais que divulgam novidades aos seus agentes; portanto, os agentes de transporte vêm correndo o risco, na maior parte das vezes, de não atingirem os seus objetivos de forma otimizada.

Pode-se dizer, a partir da regionalização das unidades produtoras de açúcar do Estado, que, mesmo com número grande de unidades dispersas pelo território nacional, o setor de transporte é bastante prejudicado com a forma pela qual os embarcadores de açúcar, representados pelas usinas e/ou tradings, se organizam, ou seja, caracterizado por ser um oligopsônio - a fatia proprietária do produto detém vantagem no momento de negociação com o segmento de transportes.

Uma ferramenta que se mostrou, também, bastante eficaz no momento de análise e entendimento dos dados numéricos coletados durante o processo de pesquisa foi a construção dos índices sazonais para o frete do açúcar para exportação pelo Porto de Santos e do preço final do açúcar comercializado pelo País. Os resultados obtidos a partir do modelo econométrico utilizado para obtenção dos índices sazonais identificaram relação inversa entre o comportamento dos fretes rodoviários do açúcar e o do preço final do produto. Esse fato evidencia a participação da demanda pelos serviços de transporte nos valores dos fretes finais picos positivos em meses de alta comercialização e negativos em meses de baixa comercialização do produto (como junho e janeiro, respectivamente).

De qualquer forma, ficou evidenciado no desenvolvimento deste estudo que o setor sucroalcooleiro (com ênfase no açúcar) apresenta grande demanda por maiores intervenções na área de infra-estrutura de transporte e armazenagem do produto final, uma vez que a efetivação de um sistema logístico de ponta incrementaria a competitividade do setor perante o mercado internacional. 
O mercado açucareiro, levando em consideração o sistema de transporte rodoviário utilizado e a formulação de seus preços de fretes, é bastante impactado em relação ao preço do produto final, ou seja, o setor de transportes possui porcentagem importante e que deve ser levada em consideração no processo de planejamento e investimento por parte dos agentes do setor. Por exemplo, na safra 2004/05, houve períodos em que o frete do açúcar chegou a representar até, aproximadamente, $10,5 \%$ do valor final do produto.

Portanto, fica a recomendação para que os agentes ligados à agroindústria canavieira realizem pesquisas sistemáticas sobre a evolução do comportamento do preço dos principais componentes de sua logística, passando não só pelo próprio valor de frete (tal como tratado neste estudo), mas também pelos custos de armazenagem eventualmente envolvidos. Devido à sazonalidade observada no processo de comercialização do açúcar, há grande variação no preço do produto e, conseqüentemente, no preço do frete rodoviário. Esses novos estudos podem vir a gerar comparações que venham a facilitar a identificação das vantagens de se armazenar ou de se escoar a produção do açúcar em determinados períodos do ano.

A melhoria no sistema de transporte - tanto do setor sucroalcooleiro como de outros setores que sejam impactados por altos custos logísticos - será resultado de uma maior integração entre os diversos setores da economia, envolvendo tanto recursos públicos quanto privados, o que certamente auxiliará o crescimento e desenvolvimento do País. 


\section{Referências}

CAIXETA FILHO, J.V. Transporte e logística no sistema agroindustrial. Preços Agrícolas, Piracicaba, v. 119, p. 2-7, setembro 1996.

CAIXETA FILHO, J.V.; GAMEIRO, A.H. (Org.) Transporte e logística em sistemas agroindustriais. São Paulo: Atlas, 2001. 218 p.

CASTRO, N.P. Intermodalidade e o transporte de longa distância no Brasil. Rio de Janeiro: Ipea, 1995. (Texto para discussão, 367).

CEPEA - Centro de Estudos Avançados em Economia Aplicada. Disponível em: $<$ http://cepea.esalq.usp.br $>$. Acesso em: 11 maio 2005.

HOFFMANN, R. Estatística para economistas. São Paulo: Pioneira Thomson Learning, 1998.

PROCANA - Centro de Informações Sucroalcooleiras. Disponível em: $<$ http://www.procana.com.br>. Acesso em: 20 abr. 2005.

RODRIGUES, R. O agronegócio. Revista Manchete, n. 2531, set. 2004.

SECEX - Secretaria do Comércio Exterior. Disponível em: <http:// www.desenvolvimento.gov.br/secex>. Acesso em: 11 maio 2005.

SIFRECA - Sistema de Informações de Fretes de Cargas Agrícolas. Disponível em: $<$ http://sifreca.esalq.usp.br $>$. Acesso em: 31 maio 2005.

Sistema Aliceweb Ministério do Desenvolvimento, Indústria e Comércio. Disponível em: $<\mathrm{http}$ ://alice.desenvolvimento.gov.br $>$. Acesso em: $17 \mathrm{abr}$. 2005.

SOARES, M. G.; GALVANI, P. R. C.; CAIXETA FILHO, J.V. Características do transporte de açúcar no Brasil. Preços Agrícolas, Piracicaba, v. 123, p. 19-22, janeiro 1997. 
UNICA - União da Agroindústria Canavieira do Estado de São Paulo. Disponível em: <http://www.unica.com.br>. Acesso em: 20 abr. 2005.

USDA - United States Department of Agriculture. Disponível em: $<$ http:/ /www.usda.gov>. Acesso em: 17 abr. 2005.

Abstract - Currently, Brazil is the greatest worldwide producer and exporter of sugar. Therefore, it is expected better defined forms to restrict high costs, which are normally present in many of the factors involved in the process of production and product commercialization. Under that context, this study searched to characterize the distribution process of the sugar produced in State of São Paulo, indicating in a summarized manner, the main agents involved within the sector, the flow observed by the product until its final delivery and the evolution of transport prices and final prices of the product during the months of the year. The method used to conduct this research was based on primary data survey and on the application of specialized econometric models. In general terms, it was observed that the transport sector within the sugar market is highly competitive and clearly open to the entrance and to the exit of companies related to the sector. The traded prices for the transportation service are defined according to the moment at which the actual demand occurs, and also depending on the presented situation and related needs. Even though, the variation in sugar freight values for export follows a trend pattern which accounts for a rise in periods of greater production of sugar and a fall in periods of lower.

Keywords: freight, transportation, sugar, logistics, exports. 
REVISTA DE ECONOMIA E AGRONEGÓCIO, VOL.5, $N^{\circ} 1$ 